\title{
High Frequency of Genetic Aberrations in Enteropathy-Type T-Cell Lymphoma
}

\author{
Anne K. Baumgärtner, Andreas Zettl, Andreas Chott, German Ott, \\ Hans Konrad Müller-Hermelink, and Petr Starostik
}

Institute of Pathology (AKB, AZ, GO, HKM-H), Würzburg University, Würzburg, Germany; Clinical Institute of Pathology (AC), Vienna General Hospital, Vienna, Austria; and Department of Pathology and Laboratory Medicine (PS), Roswell Park Cancer Institute, Buffalo, New York

\begin{abstract}
SUMMARY: To define genetic aberrations playing a role in the development of enteropathy-type T-cell lymphoma (ETL), we examined 26 such tumors using a battery of 47 microsatellite markers. The most frequent aberration (seen in $40 \%$ of informative genotypes) was amplification of genomic material in region 9q34 encompassing c-abl and Notch-1 gene loci. Other frequent amplifications were detected in regions 5q33.3-34 and 7q31 (both in more than 30\%). Multiple losses of heterozygosity were detected in 6p24, 7p21, 17q23-25, regions containing putative tumor suppressor genes, and in the p53 locus in 17p13.1. Analysis of the pattern of occurrence of these aberrations revealed existence of two ETL subgroups: one of them characterized by the 9q34 aberration and another smaller one showing allelic imbalances in 3q27. These two aberrations were mutually exclusive. Microsatellite instability (MSI) was detected in $69 \%$ of the examined lymphomas; the percentage of MSI-positive genotypes per tumor ranged from $2 \%$ to $12 \%$. The spectrum of genetic alterations detected showed patterns dependent on morphology. Monomorpic ETLs displayed frequently biallelic TCR- $\gamma$ gene rearrangement $\left(p=0078, \chi^{2}\right.$ test). They showed a different pattern and fewer allelic imbalances (no 3q27, 4q28, 13q14, fewer 5q21, or 5q33.3-34 aberrations) and a lower frequency of MSI than pleomorphic ETLs. (Lab Invest 2003, 83:1509-1516).
\end{abstract}

E nteropathy-type T-cell lymphoma (ETL) is the most serious complication of celiac disease (CD) (Ferguson and Kingstone, 1996), a condition in which individuals exhibit increased immunologic responsiveness to prolamins such as dietary wheat gliadin. Based on the results of recent prospective investigations, CD is a common disease and may affect as many as 1 in 200 to 300 people in Western countries. Only in 1978 was this lymphoma characterized by Isaacson and Wright as a single entity (1978a, b). Subsequently, it was included as "intestinal T-cell lymphoma" (with or without enteropathy) in the REAL (Revised European American classification of lymphoid neoplasms) classification (Harris et al, 1994) and coined "enteropathy-type T-cell lymphoma" in the World Health Organization lymphoma classification (Isaacson et al, 2001). The majority of ETLs are composed of pleomorphic medium-sized to large, sometimes anaplastic cells that are usually $\mathrm{CD} 3^{+}, \mathrm{CD}^{+}$, $\mathrm{TIA}^{-} 1^{+}, \mathrm{CD}^{-}$, and $\mathrm{CD}^{-}$. In roughly $20 \%$ of the cases, the cells are small- to medium-sized and express CD3, CD7, CD8, and CD56 (Chott et al, 1998).

Most ETL patients show the HLA genotype DQA $1{ }^{\star} 0501$ and $\mathrm{DQB} 1{ }^{*} 0201$, typical for $\mathrm{CD}$, which points at a possible common origin of both diseases

\section{DOI: 10.1097/01.LAB.0000090157.13040.58}

Received June 4, 2003

Address reprint requests to: Dr. Petr Starostik, Roswell Park Cancer Institute, Department of Pathology and Laboratory Medicine, Elm and Carlton Streets, Buffalo, New York 14263. E-mail:petr.starostik@roswellpark.org
(Howell et al, 1995). Cell of origin of this lymphoma is considered to be the intraepithelial $\mathrm{T}$ lymphocyte. Cytologically normal intraepithelial $T$ lymphocytes abundantly present in refractory CD (CD not alleviated by glutein-free diet), in ulcerative jejunitis, and in the enteropathic mucosa in ETL share an identical aberrant phenotype with ETL and are clonal (Bagdi et al, 1999). They are therefore considered a neoplastic population which, in the absence of concurrent overt ETL, may represent the first step in ETL lymphomagenesis (intraepithelial lymphoma) and may have already persisted for years (Carbonnel et al, 1998). These circumstances suggest sequential evolution of a clonally restricted T-cell population into an aggressive neoplasm. The genetic events required for such a transformation are not known. Speculations abound regarding the role of a persistent antigen stimulus by glutein in such a process. Distinct genetic aberrations, however, are needed to drive the process further as evidenced by long-term CD patients who display clonal T-cell populations without any evidence of a lymphoma (Daum et al, 2000; Isaacson, 2000).

There are several case reports on ETL karyotype in the published literature (Carbonnel et al, 1994; Ott et al, 1998; Wright et al, 1991). However, no consistent primary chromosomal aberration was described so far. The first work pinpointing the most common aberrations characteristic of this lymphoma is the comparative genomic hybridization $(\mathrm{CGH})$ work of Zettl et al (2002), who found recurrent gains of genetic material on chromosomal arms $9 \mathrm{q}$ (in $58 \%$ of cases), 
$7 q(24 \%), 5 q(18 \%)$, and 1q (16\%) as well as recurrent losses on chromosomes $8 p$ and $13 q$ (24\% each) and 9p (18\%).

To further evaluate genetic aberrations playing a role in ETL pathogenesis and pinpoint candidate genes whose dysfunction occurs during lymphomagenesis, we analyzed 26 ETL cases using a battery of 47 microsatellite markers. We identified several alterations characteristic for this lymphoma and show how these genetic abnormalities correlate with clinical features of the individual cases.

\section{Results}

\section{ETLs Show Frequent Genomic Aberrations}

Twenty-six ETLs were screened for genetic aberrations using 47 microsatellites spanning over 26 chromosomal regions (Table 1). These regions harbor loci of known and putative tumor suppressor genes and oncogenes or were shown to display frequent chromosomal aberrations in a previous CGH study (Zettl et al, 2002). To reliably distinguish loss of heterozygosity (LOH) from genomic amplification, multiplex PCR reactions with the marker in question and minimally one other marker used as an internal control were performed. Additionally, the microsatellite analysis results were compared with CGH data, which were available on $58 \%$ of these tumors. Of 1214 genotypes, 38 were

Table 1. Forty-Seven Microsatellite Repeats Used in the Analysis of Enteropathy-Type T-Cell Lymphoma

\begin{tabular}{ll}
\hline \multicolumn{1}{c}{ Marker } & $\begin{array}{c}\text { Chromosomal } \\
\text { region }\end{array}$ \\
\hline D1S468, D1S214 & $1 p 36$ \\
D1S237, D1S2827 & $1 q 41$ \\
D3S4103, D3S1300 & $3 p 14.2$ \\
D3S1261 & $3 p 14.1$ \\
D3S1530, D3S1262 & $3 q 27.2$ \\
FGA & $4 q 28$ \\
D5S82, D5S346 & $5 q 21.1$ \\
D5S422, D5S498 & $5 q 33.3-34$ \\
D6S470, D6S1721 & $6 p 24$ \\
D6S447 & $6 q 21$ \\
D6S310 & $6 q 24.1$ \\
D6S441 & $6 q 25.2$ \\
D7S507, D7S493 & $7 p 21$ \\
D7S501, D7S486 & $7 q 31$ \\
D8S1820, D8S1734 & $8 p 21$ \\
D8S1712, D8S1836 & $8 q 24$ \\
D9S2136, D9S1748 & $9 p 21$ \\
D9S290, D9S1847 & $9 q 34$ \\
D11S1356, D11S925 & $11 q 23$ \\
D13 S153, D13 S319 & $13 q 14.2$ \\
D15 S231 & $15 q 13.3$ \\
D15 S114 & $15 q 24.3$ \\
D16 S3070, D16 S3114 & $16 p 13$ \\
p53p, TP53CA & $17 p 13.1$ \\
D17S939, D17S784, D17S785 & $17 q 23-25$ \\
D18S474, D18S497, D18S462 & $18 q 21-23$ \\
\hline
\end{tabular}

positive for microsatellite instability (MSI) (3.1\%). Of the 907 genotypes that could be evaluated for allelic imbalance, 185 (20.4\%) of them were positive for an aberration. Seventy genotypes showed an amplification $(7.7 \%)$ and 105 were LOH-positive (11.6\%). The nature of the allelic imbalance ( $\mathrm{LOH}$ versus amplification) could not be determined in an additional 10 genotypes (1.1\%).

\section{9q34 Amplification is the Most Frequent Allelic Imbalance Detected in ETL}

The most frequent allelic imbalance (44\% of informative genotypes) (Fig. 1) detected by microsatellite analysis in this study was localized to chromosomal region 9q34 analyzed using microsatellites D9S290 and D9S1847 (4 cM apart, flanking c-abl and Notch-1 genes). Ten (40\%) patients showed an amplification of genetic material in this region; in an additional case, the nature of the allelic imbalance could not be determined as the lymphoma showed an $\mathrm{LOH}$ in the D9S1748 locus and concurrently an amplification in the D9S290 locus.

\section{Other Consistent Allelic Imbalances}

Several additional aberrations occurred at a rather high frequency ( $>30 \%$ ) (Fig. 1) in these lymphomas and thus seemed to play an important role in lymphomagenesis. Eleven lymphomas (42.3\% of informative genotypes) showed an allelic imbalance in the 17q23-25 region analyzed with microsatellites D17S939, D17S784, and D17S785. Nine lymphomas showed deletions with all three markers (34.6\%), and two $(7.7 \%)$ displayed amplifications. Ten lymphomas (38.5\%) revealed allelic imbalances in chromosomal region 5q33.3-34. Eight of the cases (30.8\%) displayed amplifications, and one case (3.8\%) showed an $\mathrm{LOH}$. In an additional case, one of the microsatellites (D5S498) showed an amplification, and the other one (D5S422) an LOH. The 7q31 chromosomal region, a

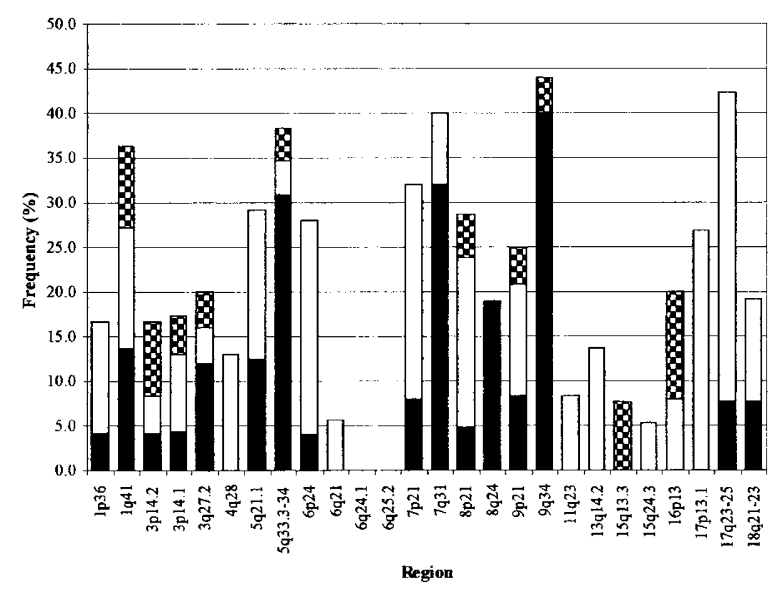

Figure 1.

Frequency of allelic imbalances detected in 26 investigated chromosomal regions in enteropathy-type T-cell lymphoma. Amplified regions are depicted as black bars; regions showing $\mathrm{LOH}$, empty bars; and allelic imbalance not otherwise specified, hatched bars. 
frequent target of aberrations in B-cell lymphomas, suffered frequent allelic imbalances also in ETL. Ten lymphomas (40\%) displayed an allelic imbalance in this region: in eight cases (32\%) an amplification, and in two tumors (8\%) an LOH. Very diverse aberrations were displayed by region 1q41 in eight lymphomas (36.4\%). Amplification or $\mathrm{LOH}$ was detected in three cases $(13.8 \%)$ of each, respectively. One additional case revealed amplification in the D1S237 locus and $\mathrm{LOH}$ in the D1S2827 locus, and another case displayed exactly the opposite abnormalities. The last locus of frequent aberrations was found in region 7p21, with eight lymphomas (32\%) showing allelic imbalances: six (24\%) cases of $\mathrm{LOH}$ and two (8\%) amplifications. Several regions containing loci of known tumor suppressor genes or oncogenes showed consistent abnormalities, albeit at a lower frequency than $30 \%$. The p53 locus in 17p13.1 showed LOH in seven lymphomas (26.9\%), and the APC gene locus showed $\mathrm{LOH}$ in $5 \mathrm{q} 21$ in four cases (16.6\%). The INK4a/ARF (p15/p16) locus in 9p21, and the retinoblastoma $(\mathrm{Rb})$ gene locus in $13 q 14$ revealed LOHs in three cases $(12.5 \%)$ each. $3 q 27$ is a chromosomal region frequently showing amplifications in B-cell lymphoma. Five cases showed allelic imbalances in this region; of these, three (12.5\%) were amplifications, another was an $\mathrm{LOH}$, and in the last one the nature of the allelic imbalance could not be reliably determined. In sharp contrast to B-cell lymphomas showing fre- quent LOHs on the long arm of chromosome 6, such aberrations were encountered only rarely in the analyzed ETLs.

\section{Subgroups of ETL Defined by Common Genomic Aberrations}

Besides the frequency of genomic deletions and amplifications, the pattern of occurrence of these changes and their associations were studied. When the results of the analysis were plotted in a diagram (Fig. 2), it became obvious that the 9q34 amplification is an unifying characteristic feature present in $40 \%$ of patients showing any allelic imbalance. This amplification is thus one of the most important abnormalities characteristic of ETL, present in both monomorphic and pleomorphic histologic types. A much smaller group was formed by five subjects showing the 3q27 allelic imbalance. None of the studied lymphomas displayed both the $3 q 27$ and $9 q 34$ aberrations concurrently.

\section{ETLs Display Low-Level MSI}

Much less frequent than allelic imbalance was the presence of $\mathrm{MSI}$ in the evaluated genotypes $(20.4 \%$ versus $3.1 \%$, respectively). Eighteen patients (69.2\%) showed MSI-positive genotypes; eight were MSInegative. There were no tumors showing high-level

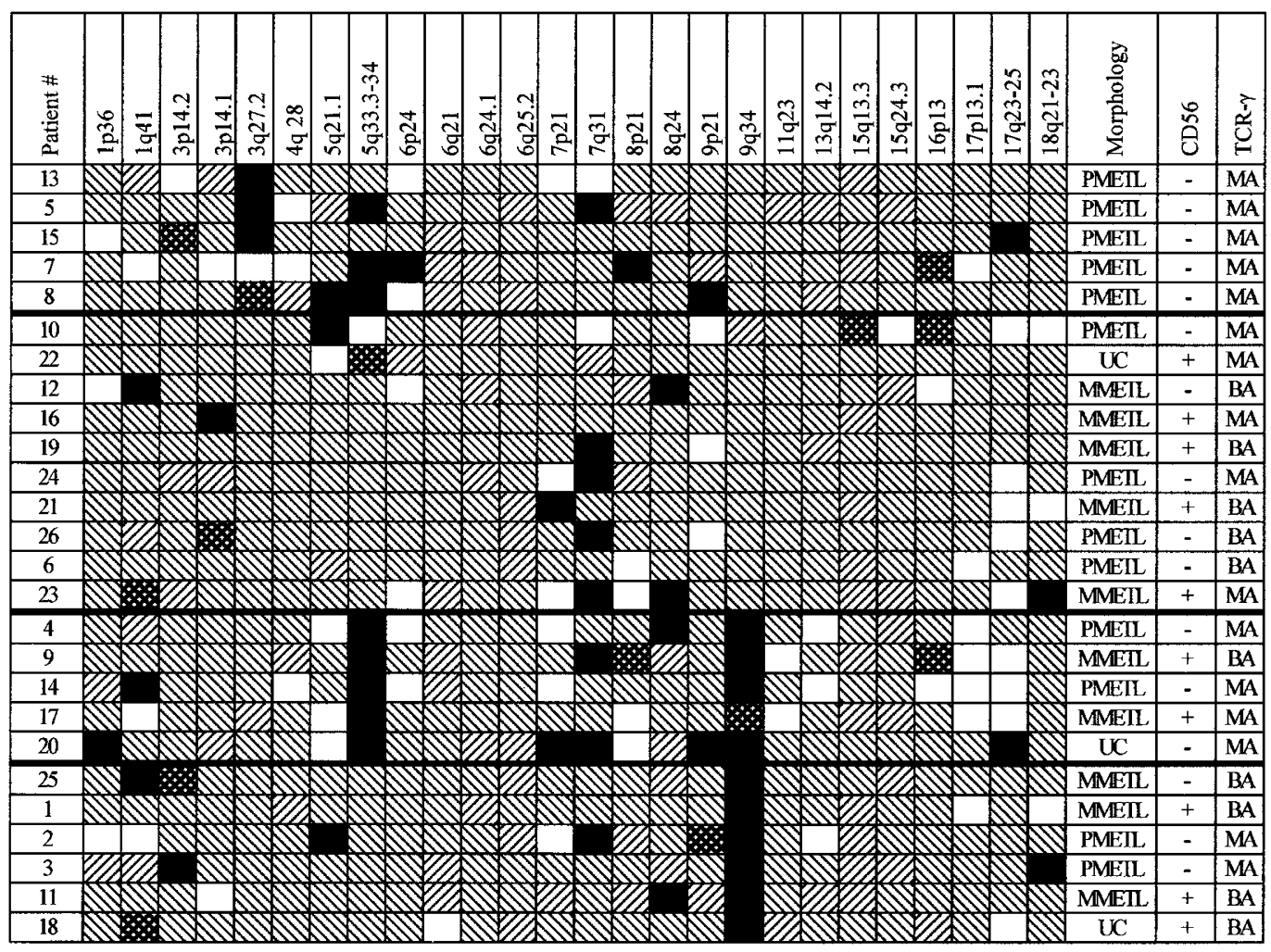

Figure 2.

Pattern of genetic aberrations in enteropathy-type T-cell lymphoma (ETL) and their relationship to morphology, immunophenotype, and TCR- $\gamma$ gene rearrangements. Chromosomal regions analyzed are shown at the top of each column. Status of each locus is indicated: retention of heterozygosity (falling stripes), not informative (ascending stripes), genomic amplification (black), LOH (empty box), and allelic imbalance not otherwise specified (hatched). MMETL = monomorphic ETL, PMETL $=$ pleomorphic ETL, UC $=$ unclassified. Results of TCR- $\gamma$ rearrangement assay are indicated as monoallelic $(M A)$ or biallelic $(B A)$ rearrangements. 
$\mathrm{MSI}$; all were MSI-L, with frequency ranging from $2 \%$ to $12 \%$ of $\mathrm{MSI}-$ positive genotypes per tumor. The most frequently MSI-positive microsatellite was the D6S441, showing $\mathrm{MSI}$ in five patients $(19,2 \%)$. D1S2827, D5S82, and D9S1847 were MSI-positive in three cases $(11.5 \%)$ each. MSI frequency did not increase with older age as we showed in a previous study on B-cell lymphomas (Starostik et al, 2000).

\section{Monomorphic ETLs Show Mostly Biallelic Rearrangement of the TCR- $\gamma$ Gene}

An interesting association was revealed between ETL morphology and the rearrangement of the TCR- $\gamma$ gene (Fig. 2). Monomorphic ETL (MMETL), which differs from pleomorphic ETL (PMETL) by its morphology (the former consist of small- to medium-sized tumor cells instead of pleomorphic larger cells as the latter), and immunophenotype (MMETL is mostly positive for the CD56 antigen; $p<0.0001, \chi^{2}$ test in this study) was the predominant ETL type showing biallelic rearrangement (BARR) of the TCR- $\gamma$ gene $\left(p=0.0078, \chi^{2}\right.$ test, Fig. 2). The BARR cases were from $78 \%$ monomorphic lymphomas; the monoallelic rearrangement-positive cases (MARR) were predominantly (79\%) pleomorphic ETLs. Altogether, 70\% monomorphic ETLs showed BARR, and 30\% were MARR-positive. Eightyfive percent of pleomorphic ETLs were MARR, and only $15 \%$ were BARR-positive.

\section{Monomorpic ETLs Display a Different Pattern of Aberrations and Less Genomic Instability}

The same monomorpic lymphomas showed a different pattern of aberrations (Fig. 3) when compared with the pleomorphic ones. They displayed no 3q27.2 $p=$ $0.034, \chi^{2}$ test), no $4 q 28$ or $13 q 14$, and fewer $5 q 21$ or 5q33.3-34 aberrations. They also showed a trend to suffer fewer genetic aberrations as measured by the

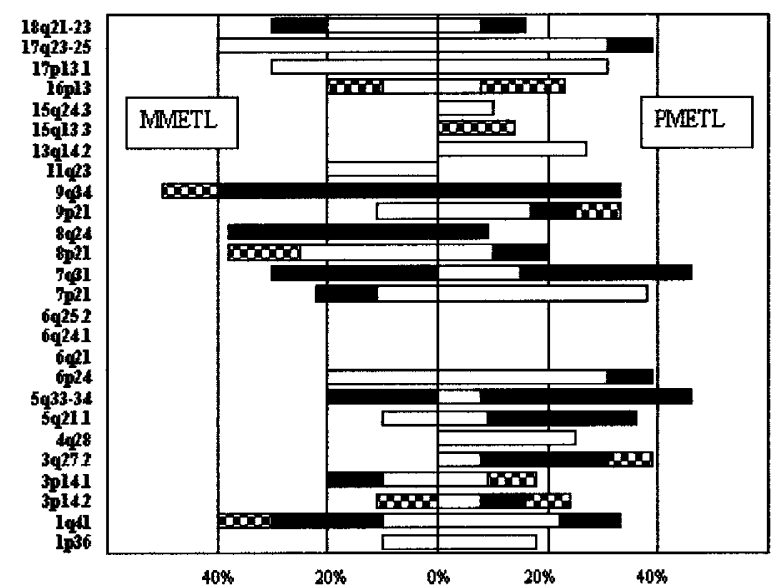

Figure 3.

Comparison of the allelotypes of monomorphic (MMETL) and pleomorphic (PMETL) enteropathy-type T-cell lymphomas (ETLs). Frequency of allelic imbalance (percentage of informative analyses) in individual regions is expressed as a bar diagram: black bar, amplification; open bar, $\mathrm{LOH}$; hatched bar, allelic imbalance not otherwise specified. The left-hand side shows results for MMETL; the right-hand side results for PMETL. microsatellite genomic instability index, (MGll, percentage of microsatellites showing any clonal aberration, either allelic imbalance or MSI, out of the total number of repeats analyzed). MMETLs had a MGII mean of $14.1 \%$ with a SD of $\pm 11.3 \%$ and PMETLs $21.4 \pm 9 \%$ (Fig. 4A, $p=0.077$, Mann-Whitney $U$ test). Especially the MSI part of the MGIl displayed a strong association with morphology. MMETLs showed a mean of $0.8 \% \mathrm{MSI}-$ positive genotypes with a SD of \pm $1.1 \%$ and PMETLs $4.9 \pm 3.8 \%$ (Fig. 4B, $p=0.002$, Mann-Whitney $U$ test). There was a similar association for the MMETLs with MGII and MSI applied for ETLs with CD56-positive status. However, the strongest association showed MGIl with the BARR of the TCR- $\gamma$ gene. BARR-positive ETLs had a MGIl mean of $12.1 \%$ and a SD of $7.1 \%$, the MARR-positive lymphomas 22.3 $\pm 10.6 \%$ (Fig. $5, p=0.014$ Mann-Whitney $U$ test). The BARR lymphomas thus displayed in general less genomic instability than the MARR cases.
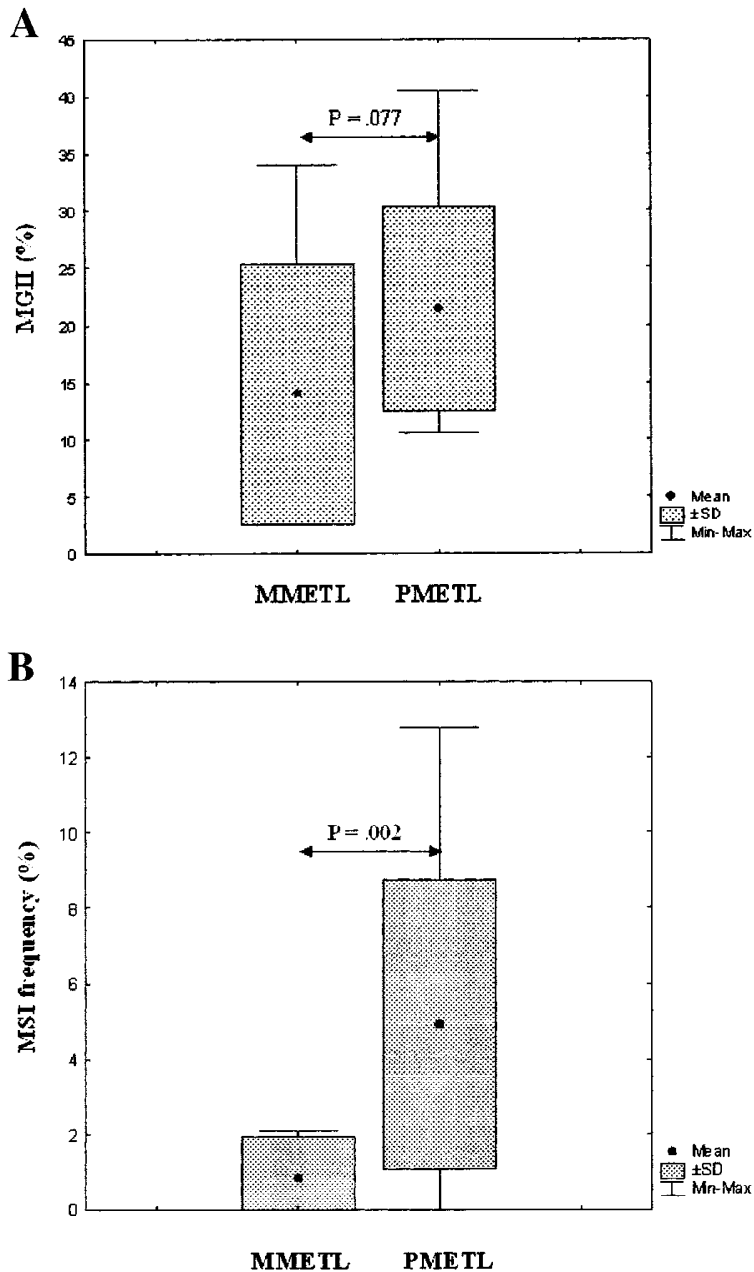

Figure 4

(A) Microsatellite genomic instability index (MGII) and (B) microsatellite instability (MSI) frequencies according to morphology. MGII was calculated as a percentage of loci showing an allelic imbalance or MSI out of the total number of repeats analyzed. The differences in MGII and MSI between monomorphic (MMETL) and pleomorphic (PMETL) enteropathy-type T-cell lymphomas (ETLs) were statistically evaluated with the Mann-Whitney $U$ test. 


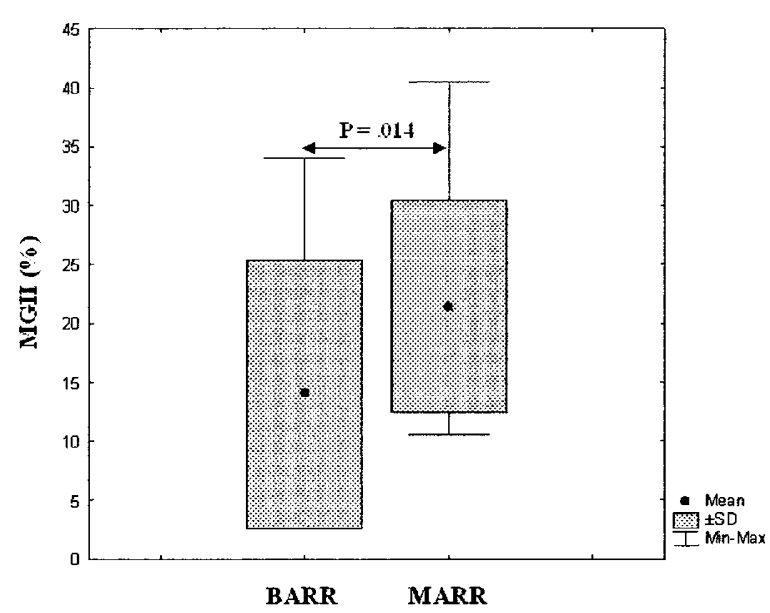

Figure 5.

Microsatellite genomic instability index (MGII) in enteropathy-type T-cell lymphomas showing mono (MARR) or biallelic (BARR) TCR- $\gamma$ gene rearrangement. The difference in MGll between depicted groups of tumors was statistically evaluated with the Mann-Whitney $U$ test.

\section{Discussion}

ETLs are tumors of heterogenous morphologic appearance, variable both between cases and sometimes even between different tumor sites in the same patient. The most frequently encountered histologic type is composed of highly pleomorphic medium to large cells followed by a lymphoma type that shows a morphology most consistent with anaplastic large cell lymphoma. The border between these two histologies is not sharp, and transition from one to the other may occur even within the same tumor. About $20 \%$ of ETLs are characterized by monotonous appearance of densly packed small- to medium-sized cells almost without any recognizeable stroma components. In contrast to ETLs with the pleomorphic/anaplastic histologies, this monomorphic variant appears to have a rather constant histology, even in cases of multiple tumors in the same patient (Chott et al, 1999). The morphologic heterogeneity of ETLs is mirrored in the immunophenotype of these tumors. The expression of the natural killer cell marker CD56 divides ETLs along their histopathologic features. The MMETLs are mostly CD56-positive tumors, and PMETLs are mostly CD56-negative. We wanted to investigate how the diverse morphology and immunophenotype are mirrored in the pattern of genetic aberrations that these tumors acquire during pathogenesis reasoning that exactly as immunophenotyping also genotyping could be used for lymphoma characterization. In contrast to B-cell lymphomas, genetic aberrations in T-cell lymphomas (and especially ETL) were much less exhaustively characterized. We screened 26 of these lymphomas with a set of 47 microsatellite markers to characterize genetic aberrations playing a role in the pathogenesis of this disease.

The most frequent genetic aberration detected in this study was allelic imbalance in the region 9q34 (in $44 \%)$. This aberration could be confirmed as amplification of genomic DNA in $40 \%$ of the studied lympho- mas. Two microsatellites were assayed in this region, D9S290 and D9S1847, approximately $4 \mathrm{cM}$ apart. 9q34 amplifications were reported previously by Renedo et al (2001) in 10\% of T-cell lymphomas and Zettl et al (2002) in 58\% of ETLs. There are several candidate genes localized in this region, whose malfunction could contribute to lymphomagenesis: c-abl is a tyrosine kinase implemented in the pathogenesis of chronic myelogenous leukemia and acute lymphocytic leukemia (Pane et al, 2002). Constitutively activated by the $t(9 ; 22)$ (q34;q11), it deregulates pathways controlling cell cycling and apoptosis. Another candidate gene is Notch-1, a transmembrane receptor responsible for the differentiation of lymphocyte precursors into $\mathrm{T}$ cells. Its role in the pathogenesis of a T-cell malignancy was identified already in 1991 by Ellisen et al (1991), who described a t(7;9)(q34;q34.3) in T-ALL. This translocation causes overexpression of Notch-1 under the influence of the T-cell receptor promoter. Such Notch-1 activation leads to leukemia induction as shown previously (Aster et al, 2000; Pear et al, 1996). Another gene possibly activated in this amplification is CDK9, a co-regulator of the progression through the cell cycle (Napolitano et al, 2002). Less probable candidates contained in the $9 q 34$ are the LIM homeo box 2 gene (Hobert and Westphal, 2000) and the VAV2 oncogene (Booden et al, 2002).

ETL is a lymphoma that carries a grave prognosis (Chott et al, 1998) corresponding to multiple genetic aberrations as shown in this study. Besides 9q34, four other different allelic imbalances were displayed by more than $35 \%$ of tumors (1q41, 5q33-34, 7q31, and 17q23-25). These regions contain unknown genes involved in lymphomagenesis. None of them were implicated in ETL pathogenesis previously. Several other regions containing known tumor suppressor genes were also found to display genetic aberrations, albeit at a lower frequency. Thus $26.9 \%$ of the informative genotypes showed $\mathrm{LOH}$ in the $\mathrm{p} 53$ locus in the region $17 \mathrm{p} 13.1 ; 16.6 \%$ showed $\mathrm{LOH}$ in the region $5 q 21$, locus of the APC gene. LOH was shown in $13 q 14$ in the retinoblastoma gene locus, and the INK4a/ARF (p15/p16) locus in 9p21 were detected in $12.5 \%$ each.

Five cases showed allelic imbalances in the 3q27 region; of these, three (12.5\%) were amplifications, one was $\mathrm{LOH}$, and in the last one the nature of the allelic imbalance could not be reliably distinguished. Interestingly, as in B-cell mucosa-associated lymphoid tissue lymphomas, this amplification defined a separate group of cases (Starostik et al, 2000a). Lymphomas showing the 3q27 allelic imbalance did not display the 9q34 amplification concurrently. The investigated ETLs were characterized not only by presence of multiple aberrations but also by rarity of aberrations of the long arm of chromosome 6 occurring frequently in B-cell lymphomas. We showed previously the increasing incidence of these genetic aberrations in mucosa-associated lymphoid tissue lymphomas as they progress into a high-grade disease, such as diffuse large B-cell lymphoma (Starostik et al, 2002). The rarity of $6 q$ aberrations in ETLs points 
at a significant difference between $\mathrm{T}$ - and $\mathrm{B}$-cell lymphomageneses.

MSI appeared also in the evaluated genotypes, albeit only at a low frequency. Nevertheless, 69\% of lymphomas displayed this low-frequency form of MSI (MSI-L, < $40 \%$ of MSI-positive microsatellites in a particular case). High-level MSI plays a wellestablished role in the development of colorectal cancer, (Jass et al, 2002); however, in lymphomas only MSI-L has been described so far (Starostik et al, $2000 \mathrm{~b})$. This type of $\mathrm{MSI}$ has not been previously shown to play a role in T-cell lymphoma. What exactly is the role of MSI-L in lymphomagenesis is still unclear. However, in this study, we show that there is a significant difference in the level of MSI in monomorphic versus pleomorphic ETLs $(p=0.002$, MannWhitney $U$ test). There is thus a selective pressure in the latter tumors for increased levels of MSI, which are further associated with increased number and different spectrum of allelic imbalances.

Bringing together morphologic, immunophenotypic, and genetic features characterizing these lymphomas, the monomorphic variant of ETL emerges as a distinct category. These tumors are mostly CD56-positive, whereas pleomorphic lymphomas are mostly CD56negative $\left(p<0.0001, \chi^{2}\right.$ test). The neoplastic lymphoma $\mathrm{T}$ cells show characteristically rearranged T-cell receptor genes. Interestingly, BARR of the $T C R-\gamma$ gene seems to associate with monomorphic tumors. Rearrangement of only one allele (MARR) can be seen predominantly in pleomorphic lymphomas ( $p$ $=0.0078, \chi^{2}$ test). In this study, 70\% monomorphic ETLs showed BARR, 30\% MARR; and 85\% pleomorphic ETLs had MARR, only 15\% BARR. The difference in the pattern of genetic aberrations further deepens the division line between the monomorphic and pleomorphic ETLs. Both lymphoma types displayed the 9q34 amplification; however, the monomorphic lymphomas did not show the $3 q 27,4 q 28$, or $13 q 14$ and rarely the 5q21 or 5q33.3-34 aberrations. Overall, genomic instability measured by the MGII (percentage of microsatellites showing either allelic imbalance or microsatellite instability) showed a trend to be lower in the monomorphic lymphomas ( $p=0.077$, MannWhitney $U$ test), especially in ETLs showing biallelic TCR- $\gamma$ gene rearrangement $(p=0.014$, Mann-Whitney $U$ test). Particularly obvious was the difference in MSI levels. Monomorphic ETLs showed a mean of $0.8 \%$ MSI-positive genotypes with a SD of $\pm 1.1 \%$, pleomorphic ETLs $4.9 \pm 3.8 \%$ ( $p=0.002$, Mann-Whitney $U$ test).

Combining morphologic, immunophenotypic, and genetic features detected in this study allowed us to closely characterize the pattern of genetic aberrations displayed by ETLs and confirm the heterogeneity of ETLs as defined by their morphologic appearance. We show that these lymphomas share a common aberration (the 9q34 amplification) but are diverse in their propensity to acquire other aberrations during pathogenesis. Characterizing the pattern of genotypic features, genetic alterations these tumors suffer during their development, not only sheds light on their patho- genesis but can also be used for tumor-type identification.

\section{Materials and Methods}

\section{Patients and Samples}

Twenty-six ETLs from the cancer registries at the Institute of Pathology of the Würzburg University in Würzburg, Germany, and the Clinical Institute of Pathology, Vienna General Hospital, Vienna, Austria, on which sufficient both tumor and normal (mostly muscle) tissue was available were selected for the study. The samples were exclusively paraffin-embedded formalin-fixed blocks. The diagnosis was established according to the criteria of the World Health Organization's classification of lymphoid tumors (Isaacson et al, 2001) by morphologic and immunophenotypic analyses of tissue sections using standard staining methods. The patient population showed an age distribution from 29 to 82 years, with a mean of 59.7 years. The male to female ratio was 1.4 ; there were 15 men and 11 women.

\section{Microscopic Dissection and DNA Extraction}

In each case, 16 serial $10-\mu \mathrm{m}$-thick tissue sections were cut. The first and last cuts were stained with hematoxylin and eosin to assure high tumor content and to use as a guidance for the following microdissection. Remaining tissue sections were additionally stained by nuclear-fast red to precisely delineate tumor-containing areas, and the collected tissue was deparaffinized using xylene before digestion. DNA extraction was performed using proteinase $\mathrm{K}$ and phenol-chloroform according to routine molecular biology protocols (Sambrook et al, 1989).

\section{Microsatellite Analysis}

Primer sequences for the amplification of microsatellite repeats listed in Table 1 were retrieved from the Genome Database (http://gdbwww.gdb.org; accessed January 2002). PCR primers were synthesized at MWG Biotech (Munich, Germany), and one oligonucleotide of each primer pair was labeled with fluorescent dye phosphoramidites FAM, TAMRA, NED, ROX, or HEX. Paired normal and tumor DNA samples from each patient were amplified with the AmpliTaq Gold DNA polymerase (ABI, Foster City, California) in multiplex PCR reactions using 50 ng genomic DNA as template under conditions specified in the Genome Database. Thirty cycles were carried out in a PE-2400 thermal cycler $(\mathrm{ABI})$ in a total volume of $20 \mu \mathrm{L}$. Aliquots of the PCR reactions were then mixed with size standard and formamide, denatured, and subjected to electrophoresis on an ABI 377 DNA Sequencer. The automatically collected data were analyzed using GeneScan and Genotyper software as described in the manufacturer's manual. Only genotypes heterozygous for a given locus were regarded to be informative; homozygosity and MSI rendered the particular locus unevaluable for $\mathrm{LOH}$ or amplification. In heterozygous 
genotypes, ratios of both alleles in normal and tumor tissues were calculated. If these ratios showed a difference of more than $20 \%$, the locus was further evaluated for possible allelic imbalance. For determination of $\mathrm{LOH}$ or amplification in a locus, first the unchanged allele was identified (by comparison with other microsatellites showing no change in the same multiplex PCR), and then the ratios of the allele showing decreased or increased signal to the unchanged allele were calculated, first for control DNA and then for the tumor. Increase of the ratio by $40 \%$ in the tumor (as compared with the control) was considered amplification; a decrease by $40 \%$ was considered $\mathrm{LOH}$. All aberrations were confirmed by repeating the experiments.

\section{TCR- $\gamma$ Clonality Control}

A PCR (PCR)-based clonality analysis assay for TCR- $\gamma$ gene rearrangement (Trainor et al, 1991) was performed on all DNA samples to assure that the control normal DNA did not contain the lymphoma clone and to stratify the tumors according to the number of $T C R-\gamma$ gene alleles rearranged.

\section{References}

Aster JC, Xu L, Karnell FG, Patriub V, Pui JC, and Pear WS (2000). Essential roles for ankyrin repeat and transactivation domains in induction of T-cell leukemia by notch1. Mol Cell Biol 20:7505-7515.

Bagdi E, Diss TC, Munson P, and Isaacson PG (1999). Mucosal intra-epithelial lymphocytes in enteropathyassociated T-cell lymphoma, ulcerative jejunitis, and refractory celiac disease constitute a neoplastic population. Blood 94:260-264.

Booden MA, Campbell SL, and Der CJ (2002). Critical but distinct roles for the pleckstrin homology and cysteine-rich domains as positive modulators of Vav2 signaling and transformation. Mol Cell Biol 22:2487-2497.

Carbonnel F, Grollet-Bioul L, Brouet JC, Teilhac MF, Cosnes J, Angonin R, Deschaseaux M, Chatelet FP, Gendre JP, and Sigaux F (1998). Are complicated forms of celiac disease cryptic T-cell lymphomas? Blood 92:3879-3886.

Carbonnel F, Lavergne A, Messing B, Tsapis A, Berger R, Galian A, Nemeth J, Brouet JC, and Rambaud JC (1994). Extensive small intestinal T-cell lymphoma of low-grade malignancy associated with a new chromosomal translocation. Cancer 73:1286-1291.

Chott A, Haedicke W, Mosberger I, Fodinger M, Winkler K, Mannhalter C, and Muller-Hermelink HK (1998). Most CD56+ intestinal lymphomas are CD8+CD5-T-cell lymphomas of monomorphic small to medium size histology. Am J Pathol 153:1483-1490.

Chott A, Vesely M, Simonitsch I, Mosberger I, and Hanak H (1999). Classification of intestinal T-cell neoplasms and their differential diagnosis. Am J Clin Pathol 111:S68-S74.

Daum S, Hummel M, Weiss D, Peters M, Wiedenmann B, Schaper F, Stein H, Riecken EO, and Foss H (2000). Refractory sprue syndrome with clonal intraepithelial lymphocytes evolving into overt enteropathy-type intestinal T-cell lymphoma. Digestion 62:60-65.
Ellisen LW, Bird J, West DC, Soreng AL, Reynolds TC, Smith SD, and Sklar J (1991). TAN-1, the human homolog of the Drosophila notch gene, is broken by chromosomal translocations in T lymphoblastic neoplasms. Cell 66:649-661.

Ferguson A and Kingstone K (1996). Coeliac disease and malignancies. Acta Paediatr Suppl 412:78-81.

Harris NL, Jaffe ES, Stein H, Banks PM, Chan JK, Cleary ML, Delsol G, De Wolf-Peeters C, Falini B, and Gatter KC (1994). A revised European-American classification of lymphoid neoplasms: A proposal from the International Lymphoma Study Group. Blood 84:1361-1392.

Hobert $\mathrm{O}$ and Westphal H (2000). Functions of LIMhomeobox genes. Trends Genet 16:75-83.

Howell WM, Leung ST, Jones DB, Nakshabendi I, Hall MA, Lanchbury JS, Ciclitira PJ, and Wright DH (1995). HLA-DRB, $-D Q A$, and -DQB polymorphism in celiac disease and enteropathy-associated T-cell lymphoma. Common features and additional risk factors for malignancy. Hum Immunol 43: 29-37.

Isaacson PG (2000). Relation between cryptic intestinal lymphoma and refractory sprue. Lancet 356:178-179.

Isaacson P and Wright DH (1978a). Intestinal lymphoma associated with malabsorption. Lancet 1:67-70.

Isaacson P and Wright DH (1978b). Malignant histiocytosis of the intestine. Its relationship to malabsorption and ulcerative jejunitis. Hum Pathol 9:661-677.

Isaacson P, Wright D, Ralfkiaer E, and Jaffe ES (2001). Enteropathy-type T-cell lymphoma. In: Jaffe ES, Harris NL, Stein $\mathrm{H}$, and Vardiman JW, editors. World Health Organization Classification of Tumours: Pathology and Genetics of Tumours of Haematopoietic and Lymphoid Tissues. Lyon: IARC Press, 208-209.

Jass JR, Whitehall VL, Young J, and Leggett BA (2002). Emerging concepts in colorectal neoplasia. Gastroenterology 123:862-876.

Napolitano G, Majello B, and Lania L (2002). Role of cyclinT/ Cdk9 complex in basal and regulated transcription (review). Int J Oncol 21:171-177.

Ott G, Katzenberger T, Siebert R, DeCoteau JF, Fletcher JA, Knoll JH, Kalla J, Rosenwald A, Ott MM, Weber-Matthiesen K, Kadin ME, and Muller-Hermelink HK (1998). Chromosomal abnormalities in nodal and extranodal CD30+ anaplastic large cell lymphomas: Infrequent detection of the $t(2 ; 5)$ in extranodal lymphomas. Genes Chromosomes Cancer 22: $114-121$

Pane F, Intrieri M, Quintarelli C, Izzo B, Muccioli GC, and Salvatore F (2002). BCR/ABL genes and leukemic phenotype: From molecular mechanisms to clinical correlations. Oncogene 21:8652-8667.

Pear WS, Aster JC, Scott ML, Hasserjian RP, Soffer B, Sklar $\mathrm{J}$, and Baltimore D (1996). Exclusive development of T cell neoplasms in mice transplanted with bone marrow expressing activated Notch alleles. J Exp Med 183:2283-2291.

Renedo M, Martinez-Delgado B, Arranz E, Garcia M, Urioste M, Martinez-Ramirez A, Rivas C, Cigudosa JC, and Benitez I (2001). Chromosomal changes pattern and gene amplification in T cell non-Hodgkin's lymphomas. Leukemia 15:16271632. 
Sambrook J, Frisch EF, and Maniatis T, editors (1989). Molecular Cloning: A Laboratory Manual. Cold Spring Harbor: Cold Spring Harbor Press.

Starostik P, Greiner A, Schultz A, Zettl A, Peters K, Rosenwald A, Kolve M, and Muller-Hermelink HK (2000a). Genetic aberrations common in gastric high-grade large B-cell lymphoma. Blood 95:1180-1187.

Starostik P, Greiner A, Schwarz S, Patzner J, Schultz A, and Muller-Hermelink HK (2000b). The role of microsatellite instability in gastric low- and high-grade lymphoma development. Am J Pathol 157:1129-1136.

Starostik P, Patzner J, Greiner A, Schwarz S, Kalla J, Ott G, and Muller-Hermelink HK (2002). Gastric marginal zone B-cell lymphomas of MALT type develop along 2 distinct pathogenetic pathways. Blood 99:3-9.
Trainor KJ, Brisco MJ, Wan JH, Neoh S, Grist S, and Morley AA (1991). Gene rearrangement in B- and T-lymphoproliferative disease detected by the polymerase chain reaction. Blood 78:192-196.

Wright DH, Jones DB, Clark H, Mead GM, Hodges E, and Howell WM (1991). Is adult-onset coeliac disease due to a low-grade lymphoma of intraepithelial T lymphocytes? Lancet 337:1373-1374.

Zettl A, Ott G, Makulik A, Katzenberger T, Starostik P, Eichler T, Puppe B, Bentz M, Muller-Hermelink HK, and Chott A (2002). Chromosomal gains at 9q characterize enteropathytype T-cell lymphoma. Am J Pathol 161:1635-1645. 